\title{
A Sociopoética como prática de pesquisa integral
}

\author{
Sociopoetics as practice of integral research \\ La Sociopoética como práctica de investigación integral
}

\author{
Jacques Gauthier ${ }^{I}$
}

\begin{abstract}
RESUMO: A partir das noções de vigilância e de vacuidade amorosas, este trabalho estuda as condições da instituição de uma ciência integrada que acolhe tanto a intuição característica do modo de fazer ciência das comunidades indígenas, afrodescendentes e populares, como o racionalismo crítico da academia. Sendo a Sociopoética uma abordagem privilegiada na configuração da identidade do pesquisador integral, o autor propõe técnicas de pesquisa intuitivas inspiradas na dança, nas sensações e no perspectivismo indígena, a fim de superar três obstáculos ao conhecimento integrado: a culpa, o medo e a falta de fé em si mesmo e no universo. Com referências em Deleuze, Guattari e Bergson, até o transe pode ganhar a dignidade de um método, na pesquisa considerada como uma conspiração do brincar.

Palavras-Chave: Enfermagem; pesquisa sociopoética; filosofia da pesquisa; interculturalidade.
\end{abstract}

ABSTRACT: Building on the notions of loving surveillance and loving emptiness, this paper studies the conditions for instituting an integrated science that welcomes both the intuition characteristic of how science is done in indigenous, Afro-American and grassroots communities, and critical academic rationalism. As Sociopoetics is particularly appropriate as an approach to shaping the identity of a comprehensive researcher, the author proposes intuitive research techniques inspired in dance, feelings and indigenous perspectivism, with a view to surmounting three obstacles to integrated knowledge: guilt, fear, and lack of faith in oneself and the universe. With references in Deleuze, Guattari and Bergson, even trance can gain the status of method in research considered a conspiracy of play.

Keywords: Nursing; sociopoetic research; research philosophy; interculturality.

RESUMEN: A partir de los conceptos de vigilancia y vacuidad amorosas, este trabajo estudia las condiciones de la institución de una ciencia integrada que da la bienvenida tanto a la intuición, característica de como se cream las ciencias indígena, afroamericana y popular, como el racionalismo crítico de la academia. Siendo la Sociopoética un enfoque primordial en la formación de la identidade del investigador integral, el autor propone técnicas intuitivas de investigación inspiradas en la danza en, las sensaciones y em el perspectivismo indígena, con el fin de superar tres obstáculos para el conocimiento integrado: la culpa, el miedo y la falta de fe en si mismo y em el universo. Con referencias en Deleuze, Guattari y Bergson, el trance puede ganar la dignidad de un método, en la investigación considerada una conspiración del jugar.

Palabras-Clave: Enfermería; investigación sociopoética; filosofía de la investigación; interculturalidad.

\section{INTRODUÇÃO}

Está em questão a integração dos saberes.

Escrevia silêncios, noites, anotava o inexprimível. Fixava vertigens. Criei todas as festas, todos os triunfos, todos os dramas. Tentei inventar novas flores, novos astros, novas carnes, novos idiomas.

Arthur Rimbaud ${ }^{1}$.

Quando trabalhamos com comunidades indígenas ou afrodescendentes percebemos a necessidade de respeitar o modo como os conhecimentos são elaborados nas culturas ancestrais. Os profissionais de saúde comunitária e educação popular sabem que sem essa forma de tradução recíproca dos saberes, populares e acadêmicos, os resultados dos esforços mútuos ficam fracos e decepcionantes.
As pesquisas que preparam a implantação das políticas públicas voltadas para essas comunidades devem igualmente tomar cuidado de favorecer essa tradução recíproca, ao saber ouvir as vozes oriundas desses meios sociais. Os referidos saberes, geralmente expressam-se através do corpo e dão ênfase a intuição. Frequentemente aparecem em forma de rituais. A academia tem seus rituais mas, como sabemos, a dimensão do sagrado, da intuição, do autoconhecimento pessoal e coletivo, pode ser ignorada sem que isso prejudique a carreira do acadêmico. Diferentemente, nessas comunidades essa dimensão pertence à identidade coletiva e pessoal.

Podemos generalizar e nos perguntar, ao seguirmos as linhas de força das aprendizagens que nos proporcionam, se nós acadêmicos não deveríamos nos inspirar nelas, ao introduzirmos no mundo acadêmico essa dimensão do sagrado, da intuição e do autoconhecimento. 
Para integrar os saberes acadêmicos e populares, há de respeitar o modo de se fazer ciência nas comunidades indígenas, afrodescendentes e outras. Digo fazer ciência, pois, o respeito implica a humildade, a renúncia à crença segundo a qual o único modo de se constituir um saber universal é seguir o modelo criado na Europa a partir da Renascença e, sobretudo, do século XIX, com a matematização do universo, a experimentação e a categorização analítica que caracterizam esse modelo. Essas comunidades nos parecem irracionais, dentro dos critérios do racionalismo crítico que a ciência eurodescendente instituiu. Mas após a magistral defesa da racionalidade do pensamento mítico, realizada por Lévi-Strauss² é difícil manter esse julgamento negativo.

Queria ir além do reconhecimento do mérito da validade racional dos saberes ancestrais e ampliar o nosso respeito para com os mesmos, ao integrar a dimensão intuitiva e sagrada numa visão transcultural do modo de fazer ciência. O conceito de vigilância amorosa $a^{3}$ para com as produções cognitivas das comunidades parceiras das nossas práticas é importante: além de reconhecer a universalidade de certos saberes criados no seu seio, há de respeitar os caminhos, os métodos, por mais estranhos (ou irracionais) que parecem. Nem necessariamente para adotá-los, mas para deixá-los vibrar e atuar no seu mundo cultural.

Talvez seja o método intuitivo o caminho mais pertinente, ao romper com o hábito de sempre começar com o racional e a análise. Podemos encontrar um bom meio termo ao dizer que o cientista eurodescendente provavelmente entrará pelo caminho da complexidade no diálogo aberto com um xamã ou um pai-de-santo, enquanto este dialogará com o cientista acadêmico a partir da intuição simples e imediata que tem dos ritmos vitais internos desse cientista. As mediações que favorecem a compreensão mútua são imagens dinâmicas que, apesar de serem de natureza intuitiva, podem ser objeto de discurso racional compartilhado pelo cientista eurodescendente, assim como afrodescendente ou indígena.

Tenho a convicção, gerada na minha história de vida, de que temos tudo a ganhar ao deixarmos igualmente esses saberes ressoar em nós, nos harmonizando com eles e até, nos transformando pela nossa própria abertura cultural e coletiva. Vou tomar um exemplo muito simples, que os profissionais do cuidar não vão estranhar: a acupuntura é aceita como saber de tipo científico pela comunidade internacional, pois, os efeitos são empiricamente verificáveis, além de já ter estudos interessantes interpretando alguns aspectos da Medicina Tradicional Chinesa (MTC), no referencial do saber biomédico ${ }^{4}$. Ora, o acupunturista aprende na sua própria prática que, além das categorias analíticas presentes na MTC, ele deve confiar na sua intuição, desde o diagnóstico até o tratamento. Essa intuição não acontece arbitrariamente: ela é ligada aos aperfeiçoamento e refinamento dos cinco sentidos. De fato, encontramos aqui o que está em jogo em qualquer tipo de medicina: um clínico, um enfermeiro confia na sua intuição e afina seus sentidos.

Ao aprofundar minha reflexão, percebi que a vigilancia amorosa pedia para se tornar vacuidade amorosa. Com efeito, somente ao me conscientizar da relativa inconsistência das minhas crenças teóricas, das minhas linhas de pesquisa, posso anular em mim os efeitos da ilusão do pensamento separado, que é o pão de hoje, a paixão e a razão de ser da academia. Logo, é na vacuidade do amor que me coloco em posição de entrega total ao outro, na investigação comum do que vem surgindo em nós como parceiros e parceiras na maravilhosa aventura humana do co-existir, do co-emergir e do co-nascer no pensamento.

Imaginemos, logo, métodos de pesquisa que deem a mesma importância ao aspecto racional das coisas e ao aspecto intuitivo e sensível - aos lados esquerdo e o direito do cérebro - e que construa pontes entre esses dois aspectos. Demos importância igual às criações coletivas dos nossos parceiros de pesquisa, indígenas, afrodescendentes ou quaisquer que sejam, e às da academia. Importância igual aos seus caminhos na constituição desses saberes e aos nossos. E mais: alteremo-nos, ao integrarmos em nós parte ou totalidade dessas criações, assim como, dos caminhos que as favorecem. Não vou propor essa alteração a todos os profissionais das áreas de saúde e de educação, apenas a quem se sente em sintonia com essa proposta. Mas qualquer um pode tranquilamente reconhecer a pertinência de desenvolver em si mesmo uma intuição e sensibilidade de qualidade, qualificada, nas suas atuações profissional e de prática de pesquisa.

É assim que podemos compreender a noção de pesquisador integral, se me permitem parafrasear a expressão de Goswami ${ }^{5}$, falando de medicina integral, baseada no assim chamado paradigma integrativo. Goswami procura uma ciência com consciência e quer integrar as dimensões científica e espiritual na cura e no cuidar ${ }^{5}$. Irei mais longe, ao afirmar o seguinte: considerando que a dimensão espiritual é a base das ciências de muitos povos, por exemplo, da fitoterapia indígena (que fala a língua de Plantas-Mestres ou Plantas-Doutoras como a Ayahuasca, a Jurema ou o Peiote) ou da psicologia iorubá (baseada em arquétipos universais do masculino e do feminino), proponho o desenvolvimento de uma ciência transcultural e integrada, que realmente integre o que nós chamamos de ciência (em referência ao racionalismo crítico), e o que esses povos chamam de ciência (em relação à dimensão espiritual, que eles atingem através de uma sensibilidade potencializada pelos seus rituais e pela fé intensa nos poderes cognitivos da intuição, assim como, de maneira radical, do transe). 


\section{MÉTODO}

\section{O método como a potência da sociopoética}

Os sociopoetas são o público alvo dessas considerações. Lembrando as cinco estrelas que os guiam no seu caminho $0^{6}$ a constituição de um grupo-pesquisador autor coletivo e cooperativo da pesquisa, sendo os acadêmicos os facilitadores da mesma; a valorização das culturas dominadas e de resistência na interpretação, e até, na criação dos dados; a mobilização de todas as capacidades cognitivas do ser humano, racionais críticas, míticas, sensíveis, intuitivas, emocionais, imaginárias, gestuais e espirituais; o uso de técnicas artísticas de pesquisa para favorecer essa integração cognitiva; enfim, a responsabilidade sociopolítica, ética, cognitiva e espiritual do grupo-pesquisador em todos os momentos da pesquisa (o que inclui seus efeitos pós-pesquisa).

Quero ser muito prático, ao sugerir algumas orientações, digamos, técnicas com seus fundamentos teóricos - que permitam aos sociopoetas fortalecerem sua identidade de pesquisador integral.

Podemos refletir a partir dos obstáculos que dificultam essa identidade (supondo que já a imaginação criadora, a humildade e a escuta sensível do outro na vacuidade amorosa se constituíram em chaves mestre da identidade sociopoética).

- O primeiro, característico da nossa herança judeu cristã é o sentimento de culpa. Não se trata apenas de um sentimento, e sim de um afeto, de uma força - uma condensação energética que bloqueia o nascimento do saber e sua expressão. Superar esse obstáculo é possível. Sugiro que o grupo-pesquisador se transforme em coletivo dançante para que esse medo seja transmutado, numa forma de alquimia espiritual, em alegria empática. Em processo de pesquisa inter e transcultural, nossos corpos já possuem energias diferenciadas e múltiplas; eles sabem muito bem disso. O que percebe o dançarino? Ele intui a quinta dimensão ${ }^{7}$ - a espiritualidade - com seu próprio corpo, desde que se deixa dançar, possuir, como as marionetes de Kleist ${ }^{8}$ ou como o corpo dos filhos de - santo dançado pelo orixá.

Outro esudioso mostra como o corpo pensa (o que sabem os indígenas e afrodescendentes) e como, ao mesmo tempo, o pensamento é uma dança virtual ${ }^{9}$. Além disso, ambos, corpo e pensamento, são rizomáticos, já que percorridos por energias que não são individuais, mas surgem da natureza e do cosmos, assim como, dos encontros dos corpos na vida social e na educação. Assim preconizo incluir a dança - cada um dançando o quê e como seu corpo sente e pensa - nas técnicas de relaxamento favorecendo a produção dos dados (lembrando que a produção de dados se faz em estado de consciência extremamente relaxado - próximo do sonho, conforme a técnica psicanalítica).

Outra possibilidade de relaxamento que enfraquece as perversas energias de culpa em nós, a ser aplicada, por exemplo, antes da análise feita na hora pelo grupo-pesquisador das suas produções artísticas, seria o dispositivo de brincar-de-bichos. A preparação para esse jogo onde cada copesquisador brinca de sentir e atuar como um animal passa por um estado meditativo de vacuidade. Aqui acho bom colocarmos uma música relaxante, enquanto os copesquisadores se deixam possuir pelo animal que encarnarão. É só encontrar uma música com grande diversidade em termos de ritmos, alturas, intensidades, timbres e outros. para que ela não induza o animal a ser encarnado. Qual o interesse de encontrarmos-criarmos, num dado grupo-pesquisador, uma dúzia de mundos-anta, e num outro, uma dúzia de mundos-onça ou uma dúzia de mundos-beija-flor? Não, há de ser astucioso o suficiente para que se encontrem no mesmo espaço-tempo da pesquisa e, quem sabe, na mesma quinta dimensão, alguns mundos onçaridos, outros, antaridos, outros beija-floridos... e assim por diante. Como sabemos, vivenciamos assim, devires-animais, ou seja, nos entregamos a frequências energéticas inacostumadas, que modificam nossa sensibilidade, logo, nossa perspectiva ${ }^{10}$, ou seja, o mundo que percebemos, conforme o perspectivismo dos povos indígenas ${ }^{11}$. Entramos assim num, Estado Alternado de Consciência (EAC) - alternado e não alterado, pois não se trata de criar uma ilusão, e sim de mudar de plano de realidade, de criar uma linha de fuga inédita e singular, dentro da vacuidade.

- O segundo obstáculo à constituição da identidade de pesquisador integral, característico do que é academicamente instituído, é o medo e falta de fé em si mesmo. A fonte do conhecimento é o amor transpessoal, e muitos são os sábios que dizem que o contrário do amor não éo ódio, e sim o medo. É possível superar esse obstáculo impar ao conhecimento autêntico através do trabalho com as sensações, com os elementais. Quem já trabalhou os seus medos profundos, arcaicos, cármicos, sabe que isso pede para o alcance do equilíbrio interno e o culto aos elementos terra, fogo, água e ar em nós. Boas técnicas de produção de dados já existem na Sociopoética que potencializam nosso equilíbrio interior, fonte de resgate de conhecimentos velados ou recalcados, através da aplicação do toque sensível. Citarei a Técnica do Jogo de Tarô e a Técnica dos cinco sentidos ${ }^{6}$. Cuidado: na Técnica do Jogo de Tarô, por exemplo, mesmo se os copesquisadores geram pequenos grupos em torno de um elemento por afinidade a fim de criar uma carta de Tarô, não se trata de repetir o que a gente já, conscientemente, sabe, e sim de se conectar a um elemental em nós, para tocá-lo de verdade. Da mesma maneira, escolher cinco matérias entre 12 , de olhos vendados e por critérios puramente táteis a fim de caracterizar o tema-gerador da pesquisa, não deve acontecer a partir da identificação da matéria e sim pela ressonância em nós do aspecto liso ou áspero, frio ou quente, contínuo ou descontínuo e outros, da mesma. Devemos reaprender a perceber, sentir, se entregar ao mundo, da mesma 
maneira que, na dança, aprendemos a deixar a dança dançar em nós. Insisto na importância do percepto, da percepção pura e da sua derivação, o perfeto - mistura de percepto e de afeto, na criação de um saber autêntico e não coberto pela sujeira do sentimentalismo, desprezo de si e autopiedade.

- O terceiro obstáculo à integralidade do pesquisador é a falta de fé no universo. Não num Deus exterior e onipotente, e sim no próprio universo no qual estamos inseridos e que está inserido em nós. O grupo-pesquisador é atravessado por afetos pré-individuais e, reciprocamente, para que ressoem forças pré-individuais, tanto para que se amplifiquem e oscilem juntas, criando ordens espontâneas imprevisíveis extremamente potentes $^{12}$, como para que se gerem assimetrias abrindo sobre dimensões desconhecidas do real, por definição é preciso, pelo menos, de um grupo.

A não ser que seja um santo, o sujeito, quando isolado, nem pode se potencializar, nem criar diferenças de potencial dentro dele, nem voltar para si mesmo com um olhar ampliado - com vistas sobre dimensões superiores e percepção de eventos mais finos. Ele precisa da fecundação do seu coração por outros corações ecoando e ressoando, criando novos ritmos, inesperados. Isso é verdadeiro em comunidades espirituais, e também em grupos desenvolvendo uma pesquisa, tais como os grupospesquisadores sociopoéticos. Por essa razão, estou convencido de que, nas pesquisas sociopoéticas, não somente coconstruímos cooperativamente o conhecimento, mas vivenciamos também um devir coletivo de ampliação espiritual. É importante os facilitadores serem conscientes de que a desindividualização das pessoas que acontece no grupo-pesquisador é a base desse devir espiritualmente ampliado. As linhas de fuga de vacuidade transcultural assim criadas sãoperspectivas-mundos diferenciadas. Existe, aliás, uma perspectiva que integra as harmonias das durações, dos ritmos vitais, das temporalidades múltiplas características de cada um. Sendo o conhecimento uma cocriação do grupo-pesquisador como um todo, filósofo coletivo e cooperativo, certa harmonização se torna cada vez mais provável, desde que o grupo acolhe e ressoa com as harmonias do universo.

Quais as técnicas que podemos aplicar para que a nossa potência cognitiva seja em fase com o saber do universo? Podemos nos inspirar na ioga, na dança até esgotamento, em rituais ou mantras, ou ainda, usando plantas-professoras indígenas como a Ayahuasca, o Peiote, a jurema ou certos tipos de rapé. Em que momento desenvolver essas técnicas? No meu ver, para produzir dados.

\section{A ConsPiração do Brincar}

Sei que tem de trabalhar com o negativo e não repudiá-lo, pois não devemos fugir da desarmonia em cada um de nós, e sim vê-la, revelá-la, aceitá-la... condição indispensável para que possamos trabalhar e conhecer autenticamente, sem ilusão nem autoengano. Mas, por outro lado, não podemos esquecer o fato de que o negativo e a desarmonia se constituem em obstáculos na geração de conhecimentos mais potentes, que consigam ver o espiritual em nós e atingir os mistérios intuitivos da quinta dimensão. Spinoza ligava intimamente o conhecimento verdadeiro e a libertação.

Da mesma maneira, podemos teorizar a desarmonia dentro do grupo: por um lado, é necessário ver a vida social e individual como ela é, com seus conflitos, sua feiura e sujeira, pois nosso projeto é um projeto de conhecimento e não de cura. Não podemos criar falsos consensos, harmonias de faz-de-conta, nem generalizações abstratas que contentam todo mundo, por cada um poder projetar o que lhe parece desejável. Em Bakhtin ${ }^{13}$ me inspirei quando criei a noção de afinição dos conceitos - querendo apontar a necessidade de se gerar conceitos que sejam polifônicos, cheios de divergências e contradições, por assim dizer com nossa condição humana múltipla e conflituosa.

Hoje, falaria de confetos - lembrando que:

- Todo confeto desenvolve-se a partir de um intuifeto: uma imagem criadora intuitiva surge em estado de relaxamento, a partir da qual se constitui o confeto logo, o mundo simbólico, com sua parte de mistério, já está presente no início da pesquisa.

- Os próprios conceitos - implicados nos confetos - são pensados em referência a Deleuze e Guattari: os conceitos não são aristotelicamente definidos em extensão e compreensão, e sim em in-tensão e poder de fazer rizoma. São ritornelos e, eles dizem o evento, não a essência ou a coisa ${ }^{14}$. São musicais, acontecimentos intensivos com variações.

Vale registrar que a concepção de transe como método remete à Bergson, que experimentou a intuição como método ${ }^{15}$.

\section{CONSIDERaÇões Finais}

Mantendo essa abordagem, que considero uma vitória da Sociopoética, acrescento também a necessidade de conseguir vivenciar um devir coletivo de ampliação espiritual, única maneira de chegar a intuições da quinta dimensão: intuições e intuicetos, misturas de conceitos e intuições. Assim configura-se o transe como método - em eco bergsoniano que concebe a intuição como método.

O que me proponho como sociopoeta é fazer com que três eixos conspirem na pesquisa: o da vacuidade (amorosa e transcultural), o da interdependência dos seres (dentro do grupo-pesquisador e entre esse filósofo coletivo e o universo) e o da diferenciação harmonizadora (ou melhor dizendo, harmonização criadora). Chamo a dança íntima que se estrutura a partir desses eixos de conspiração do brincar. 


\section{REFERÊNCIAS}

1.Rimbaud A. Oeuvres complètes. Paris (Fr): Gallimard; 2009.

2.Lévi-Strauss C. La penséesauvage. Paris (Fr): Plon; 1962.

3.Gauthier J. Do mar ao orvalho: aprendendo a vigilância amorosa. In: Grando BS, Passos LA. O eu e o outro na escola: contribuições para incluir história e a cultura dos povos indígenas na escola. Cuiabá (MT): EdUFMT; 2010. p. 17-9.

4.Jacques LM. As bases científicas da medicina tradicional chinesa. São Paulo: Annablume; 2005.

5.Goswami A.O médico quântico:orientações de um físico para a saúde e a cura. São Paulo: Cultrix; 2006.

6 . Gauthier J. O oco do vento: metodologia da pesquisa sociopoética e estudos transculturais. Curitiba (PR): CRV; 2012.

7.Gauthier J.Interferências culturais: @ pesquisador@ integral na vacuidade amorosa. Campo Grande (MS):
Ed. UCDB ; 2014.

8.KleistH. Sur le théâtre de marionnettes. Paris (Fr): Sillage ; 2010.

9.Doganis B. Pensées du corps: la philosophie à l'épreuve des arts gestuels japonais (danse, théâtre, arts martiaux). Paris (Fr): Les Belles Lettres ; 2012.

10.Deleuze G, Guattari F. Mille plateaux. Paris (Fr): Minuit ; 1980.

11.Castro EV. A inconstância da alma selvagem. São Paulo: Cosac Naify; 2013.

12.Prigogine I, Stengers I. La fin des cerrtitudes. Paris (Fr): Odile Jacob; 2001.

13.Bakhtine M. Le marxisme et la philosophie du langage: essai d'application de la méthode sociologique en linguistique. Paris (Fr): Minuit ; 1977.

14.Deleuze G, Guattari F. Qu’est-ce que la philosophie? Paris (Fr): Minuit; 1991.

15.Bergson H.O pensamento e o movento. São Paulo: Martins Fontes; 2006. 